CrossMark CrossMark
\& click for updates

Cite this: J. Mater. Chem. C, 2015, 3, 5199

\section{Fabrication of flexible polymer-GaN core-shell nanofibers by the combination of electrospinning and hollow cathode plasma-assisted atomic layer deposition $\uparrow$}

\author{
Cagla Ozgit-Akgun, ${ }^{\text {ab }}$ Fatma Kayaci, ${ }^{a b}$ Sesha Vempati, ${ }^{a}$ Ali Haider, ${ }^{a b}$ \\ Asli Celebioglu, ${ }^{\mathrm{ab}}$ Eda Goldenberg, ${ }^{\mathrm{a}}$ Seda Kizir, ${ }^{\mathrm{ab}}$ Tamer Uyar $^{\mathrm{ab}}$ and Necmi Biyikli*ab
}

\begin{abstract}
Here we demonstrate the combination of electrospinning and hollow cathode plasma-assisted atomic layer deposition (HCPA-ALD) processes by fabricating flexible polymer-GaN organic-inorganic core-shell nanofibers at a processing temperature much lower than that needed for the preparation of conventional GaN ceramic nanofibers. Polymer-GaN organic-inorganic core-shell nanofibers fabricated by the HCPA-ALD of $\mathrm{GaN}$ on electrospun polymeric (nylon 6,6) nanofibers at $200{ }^{\circ} \mathrm{C}$ were characterized in detail using electron microscopy, energy dispersive X-ray analysis, selected area electron diffraction, X-ray diffraction, X-ray photoelectron spectroscopy, photoluminescence measurements, and dynamic mechanical analysis. Although transmission electron microscopy studies indicated that the process parameters should be further optimized for obtaining ultimate uniformity and conformality on these high surface area 3D substrates, the HCPAALD process resulted in a $\sim 28 \mathrm{~nm}$ thick polycrystalline wurtzite GaN layer on polymeric nanofibers of an average fiber diameter of $\sim 70 \mathrm{~nm}$. Having a flexible polymeric core and low processing temperature, these core-shell semiconducting nanofibers might have the potential to substitute brittle ceramic GaN nanofibers, which have already been shown to be high performance materials for various electronic and optoelectronic applications.
\end{abstract}

Received 4th February 2015 Accepted 13th April 2015

DOI: $10.1039 / \mathrm{c} 5 \mathrm{tc00343a}$

www.rsc.org/MaterialsC

\section{Introduction}

During the last few decades, gallium nitride (GaN), which is probably the most important semiconductor other than silicon, has been frequently used in optoelectronic devices operating in the blue region of the spectrum. GaN has a direct and relatively large band gap of $3.4 \mathrm{eV}$, high bond strength, good thermal conductivity, and high breakdown field. Therefore it is suitable for use in high power devices, as well as other devices operating at high temperatures and/or hostile environments. ${ }^{1}$ Besides their thin film counterparts, one-dimensional (1D) semiconducting GaN nanostructures have also recently attracted much attention due to their potential applications in various device structures. ${ }^{2}$ Single crystal or polycrystalline GaN nanostructures such as nanobelts, nanowires, or nanotubes with high aspect ratios were synthesized using different strategies including vaporliquid-solid crystal growth, ${ }^{3-8}$ laser-assisted catalytic growth, ${ }^{9,10}$

\footnotetext{
${ }^{a}$ UNAM-National Nanotechnology Research Center, Bilkent University, Ankara, 06800, Turkey.E-mail: ozgit@bilkent.edu.tr, biyikli@unam.bilkent.edu.tr

${ }^{b}$ Institute of Materials Science and Nanotechnology, Bilkent University, Ankara, 06800, Turkey

$\dagger$ Electronic supplementary information (ESI) available. See DOI: 10.1039/c5tc00343a
}

template synthesis, ${ }^{11,12}$ and etching. ${ }^{13,14}$ The synthesis of randomly oriented or aligned continuous polymorphic GaN nanofibers having the wurtzite structure was also demonstrated by a few research groups. These reports are electrospinning-based processes, where the electrospun composite nanofibers containing the polymer and Ga precursor were subjected to calcination for the removal of organic components and subsequent high temperature $\left(\geq 850{ }^{\circ} \mathrm{C}\right)$ nitridation in an ammonia atmosphere. ${ }^{15-21}$ These GaN nanofibers (crystallite sizes $<20 \mathrm{~nm}$ ) exhibited cathodoluminescence ${ }^{19}$ and photoconductivity, ${ }^{20}$ and were successfully applied in UV detection ${ }^{20}$ and ethanol sensing. ${ }^{21}$

Several research groups combined electrospinning and atomic layer deposition (ALD) to synthesize hollow inorganic nanofibers (or nanotubes) of $\mathrm{Al}_{2} \mathrm{O}_{3},{ }^{22} \mathrm{AlN},{ }^{23} \mathrm{AlN} / \mathrm{BN},{ }^{24} \mathrm{HfO}_{2},{ }^{25}$ $\mathrm{SnO}_{2}{ }^{26,27} \mathrm{TiO}_{2}{ }^{28,29} \mathrm{TiO}_{2} / \mathrm{ZnO},{ }^{30}$ and $\mathrm{ZnO}^{31-34}$ Core-shell $\mathrm{CuO}-\mathrm{ZnO},{ }^{35} \mathrm{NiFe}_{2} \mathrm{O}_{4}-\mathrm{TiO}_{2},{ }^{36}$ polyacrylonitrile-ZnO, ${ }^{37} \mathrm{SnO}_{2}-\mathrm{ZnO},{ }^{38}$ $\mathrm{TiO}_{2}-\mathrm{ZnO},{ }^{39,40} \mathrm{WO}_{3}-\mathrm{TiO}_{2}{ }^{41}$ and $\mathrm{ZnO}^{4} \mathrm{TiO}_{2}{ }^{40}$ nanofibers, Nb-doped $\mathrm{TiO}_{2}$-supported $\mathrm{Pt}$ nanoparticle catalysts, ${ }^{42}$ and microtube-in-microtube $\mathrm{ZnAl}_{2} \mathrm{O}_{4}$ assemblies ${ }^{43}$ were also fabricated successfully using this process combination. Recently our group synthesized photocatalytic polymer-ZnO core-shell nanofibers using the same approach. ${ }^{44-47}$ Besides showing high photocatalytic activity, the fabricated mats could also be easily 
handled and folded as a freestanding material due to the flexible polymeric core. Until recently, the fabrication of such flexible nanofibers with the GaN shell has been limited by the absence of a low-temperature self-limiting ALD process for GaN. The temperatures required for the thermal ALD using metal-organic or halogenated Ga precursors were too high to be compatible with polymeric substrates. ${ }^{48-51}$ In order to lower the reaction temperatures, $\mathrm{NH}_{3}$ was activated via plasma during the trimethylgallium $\left(\mathrm{GaMe}_{3}\right)-\mathrm{NH}_{3}$ ALD process; however the resulting films were contaminated with $\sim 20$ at\% oxygen due to the sputtering of the inductively coupled quartz plasma source. ${ }^{52,53}$ Recently, we deposited wurtzite GaN thin films with low impurity concentrations (O, C $<1$ at\%) in a self-limiting fashion at $200{ }^{\circ} \mathrm{C}$ using an ALD system coupled with a hollow cathode plasma source. ${ }^{54}$ The (opto)electronic properties of the GaN thin films were studied via fabrication of transistors ${ }^{55}$ and UV photodetectors. ${ }^{56}$

Here we performed the fabrication of flexible polymer-GaN organic-inorganic core-shell nanofibers using the combination of electrospinning and hollow cathode plasma-assisted ALD (HCPA-ALD) processes. Following the fabrication of pristine polymeric (nylon 6,6) nanofibers with an average fiber diameter of $\sim 70 \mathrm{~nm}$ by electrospinning, 1000 cycles of GaN were deposited on these nanofibers at $200{ }^{\circ} \mathrm{C}$ via HCPA-ALD using $\mathrm{GaMe}_{3}$ and $\mathrm{N}_{2} / \mathrm{H}_{2}$ plasma as the Ga and $\mathrm{N}$ sources, respectively. Pristine nylon 6,6 and/or nylon-GaN core-shell nanofibers were characterized in detail using electron microscopy, energy dispersive X-ray analysis (EDX), selected area electron diffraction (SAED), X-ray diffraction (XRD), X-ray photoelectron spectroscopy (XPS), photoluminescence (PL) measurements, and dynamic mechanical analysis (DMA).

\section{Experimental}

\section{Fabrication of polymer-GaN core-shell nanofibers}

Materials. Nylon 6,6 (relative viscosity $230000-280000$ ) pellets and formic acid (98-100\%) were purchased from Sigma-Aldrich. For the HCPA-ALD process, $\mathrm{GaMe}_{3}$ purchased from Sigma-Aldrich, 5N-grade $\mathrm{N}_{2}$ and $\mathrm{H}_{2}$ gases, and $\mathrm{Ar}$ gas purchased from Linde were used as the $\mathrm{Ga}$ precursor, $\mathrm{N}$-containing plasma gas, and carrier gas, respectively. $\mathrm{N}_{2}, \mathrm{H}_{2}$ and $\mathrm{Ar}$ gases were further purified using MicroTorr gas purifiers, while the other materials were used without any purification.

Electrospinning of nylon 6,6 nanofibers. $8 \mathrm{wt} \%$ nylon 6,6 pellets were dissolved in formic acid for $3 \mathrm{~h}$ to yield a homogeneous clear solution. This solution was then loaded in a $3 \mathrm{ml}$ syringe fitted with a metallic needle with $\sim 0.8 \mathrm{~mm}$ inner diameter. A syringe was fixed horizontally on the syringe pump (KD Scientific, KDS 101) and polymer solution was pumped at a feed rate of $1 \mathrm{ml} \mathrm{h}^{-1}$. Electrospinning of the solution was performed by applying a voltage of $\sim 15 \mathrm{kV}$ to the metal needle tip via a high voltage power supply (Matsusada Precision, AU Series). The tip-to-collector distance was set to $\sim 10 \mathrm{~cm}$. The collector was wrapped with clean $\mathrm{Al}$ foil and grounded. As the solvent evaporated, solidified nylon 6,6 nanofibers were deposited on the collector. The electrospinning setup was enclosed in a
Plexiglas box, which allowed the electrospinning process to be carried out at $24{ }^{\circ} \mathrm{C}$ and $30 \%$ relative humidity.

Hollow cathode plasma-assisted ALD of GaN. HCPA-ALD of GaN was carried out at $200{ }^{\circ} \mathrm{C}$ in a Fiji F200-LL ALD reactor (Ultratech/Cambridge NanoTech Inc.) equipped with a remote stainless steel hollow cathode plasma source (Meaglow Ltd). Prior to deposition, $\mathrm{GaMe}_{3}$ cylinder was cooled to $\sim 6{ }^{\circ} \mathrm{C}$ and stabilized at this temperature using a home-made Peltier system. Nylon 6,6 nanofibers collected on an $\mathrm{Al}$ foil (having a circular area of $\sim 80 \mathrm{~cm}^{2}$ ) was fixed at the center of the substrate holder. The sample was loaded into the reactor via a load-lock and maintained at the deposition temperature for at least $20 \mathrm{~min}$ before the process was initiated. $\mathrm{GaMe}_{3}$ pulses and plasma gases were carried through separate lines with 30 and $100 \mathrm{sccm}$ of Ar, respectively. The base pressure (with Ar carrier flows) was $\sim 150$ mTorr. 1000 cycles of GaN were deposited, where one HCPA-ALD cycle consists of $0.015 \mathrm{~s} \mathrm{GaMe}_{3} / 10 \mathrm{~s}$ Ar purge/40 s $50 / 50 \mathrm{sccm} \mathrm{N}_{2} / \mathrm{H}_{2}$ plasma $(300 \mathrm{~W}) / 10 \mathrm{~s}$ Ar purge.

\section{Characterization}

Scanning electron microscopy (SEM) imaging of pristine nylon 6,6 and nylon-GaN core-shell nanofibers was performed using a FEI Quanta 200 FEG SEM. Prior to the imaging, $\sim 5 \mathrm{~nm} \mathrm{Au} / \mathrm{Pd}$ alloy was sputter-deposited on SEM samples in a Precision Etching Coating System (PECS, Gatan, Model 682). Transmission electron microscopy (TEM), SAED, and EDX were carried out using an FEI Tecnai G2 F30 TEM (operating at $300 \mathrm{kV}$ ). For these analyses, the sample was peeled off from its support (i.e., $\mathrm{Al}$ foil), dispersed in ethanol and drop-casted onto a $\mathrm{Cu}$ TEM grid. XRD patterns of the freestanding samples, which were placed carefully on a zero-background sample holder, were recorded in the range of $2 \theta=15$ to $75^{\circ}$ using a PANalytical $\mathrm{X}$ 'Pert Pro Multi Purpose X-ray diffractometer with $\mathrm{Cu} \mathrm{K} \alpha$ radiation $\left(\lambda=1.5418 \AA\right.$ ). The step size and counting time were $\sim 0.05^{\circ}$ and $300 \mathrm{~s}$ (or $2000 \mathrm{~s}$ ), respectively. The chemical composition and bonding states of the pristine nylon 6,6 and nylon-GaN core-shell nanofibers were investigated by XPS (Thermo Fisher Scientific) with a monochromatic $\mathrm{Al} \mathrm{K} \alpha$ radiation. The pass energy, step size, and spot size were $30 \mathrm{eV}, 0.1 \mathrm{eV}$, and $400 \mathrm{~mm}$, respectively. All spectra were corrected for charging by shifting peaks with respect to the adventitious $\mathrm{C}$ peak located at $\sim 284.8 \mathrm{eV}$. Peak deconvolution was performed using the Avantage Software without applying any restrictions to spectral location and full width at half maximum values. PL measurements were carried out using a time-resolved fluorescence spectrophotometer (Jobin Yvon, model FL-1057 TCSPC) within the wavelength range of 300$500 \mathrm{~nm}$. The excitation wavelength was $\sim 270 \mathrm{~nm}$. A dynamic mechanical analyzer (DMA, Q800 TA Instruments) was used to determine the mechanical performances of pristine nylon 6,6 and nylon-GaN core-shell nanofibers. Measured samples were rectangular in shape, having an approximate size of $\sim 10 \mathrm{~mm}$ (gap) $\times \sim 2.5 \mathrm{~mm}$ (width) $\times \sim 0.14 \mathrm{~mm}$ (thickness). The stressstrain curve of the nanofibrous web was obtained at a constant rate of $0.5 \mathrm{~N} \mathrm{~min}{ }^{-1}$ and the average values were calculated by performing three measurements at room temperature. The storage modulus of the composite nanofibers was recorded in 
the range of $75-200{ }^{\circ} \mathrm{C}$ at a heating rate of $3{ }^{\circ} \mathrm{C} \mathrm{min}^{-1}$ by applying an amplitude of $15 \mu \mathrm{m}$.

\section{Results and discussion}

Representative SEM images of pristine nylon 6,6 nanofibers are given in Fig. 1a and b. From these images, it is seen that the electrospinning process described in previous section resulted in bead-free polymeric nanofibers with a smooth morphology and uniform fiber diameter. The average fiber diameter of these pristine nylon 6,6 nanofibers was calculated by taking $\sim 100$ measurements from high magnification SEM images. The average value is $68 \pm 12 \mathrm{~nm}$, which is in good agreement with the values reported previously by us for the very same process. ${ }^{23,44}$ Fig. 1c and d are the representative SEM images of nylon-GaN core-shell nanofibers at different magnifications. The images show that GaN layer was deposited in a very uniform and conformal fashion on the individual nylon 6,6 nanofibers without destroying the overall morphology. The average fiber diameter of nylon-GaN core-shell nanofibers was also calculated by averaging $\sim 100$ measurements from high magnification SEM images and found to be $123 \pm 24 \mathrm{~nm}$. Using this data the average film thickness for the deposited GaN was found to be $\sim 27.5 \mathrm{~nm}$, which corresponds to a growth per cycle (GPC) value of $\sim 0.28 \AA$. Previously, the growth of GaN on Si substrates (for $\mathrm{GaMe}_{3}$ pulse length of $0.03 \mathrm{~s}$ ) was shown to be substrate-enhanced with a GPC of $0.47 \AA$ for 75 cycles decreasing gradually to $\sim 0.22 \AA$ for 900 cycles. $^{54}$ Here, it should also be noted that the $0.015 \mathrm{~s}$ and $0.03 \mathrm{~s}$ of $\mathrm{GaMe}_{3}$ pulse lengths both resulted in a similar GPC and thickness uniformity over a 4 in. Si substrate ( $0.23 \AA$ and $\pm 1.31 \%$ vs. $0.22 \AA$ and $\pm 0.77 \%) .{ }^{54}$ Therefore, in this study $\mathrm{GaMe}_{3}$ pulse length of $0.015 \mathrm{~s}$ was used in the first step of the HCPA-ALD cycle.
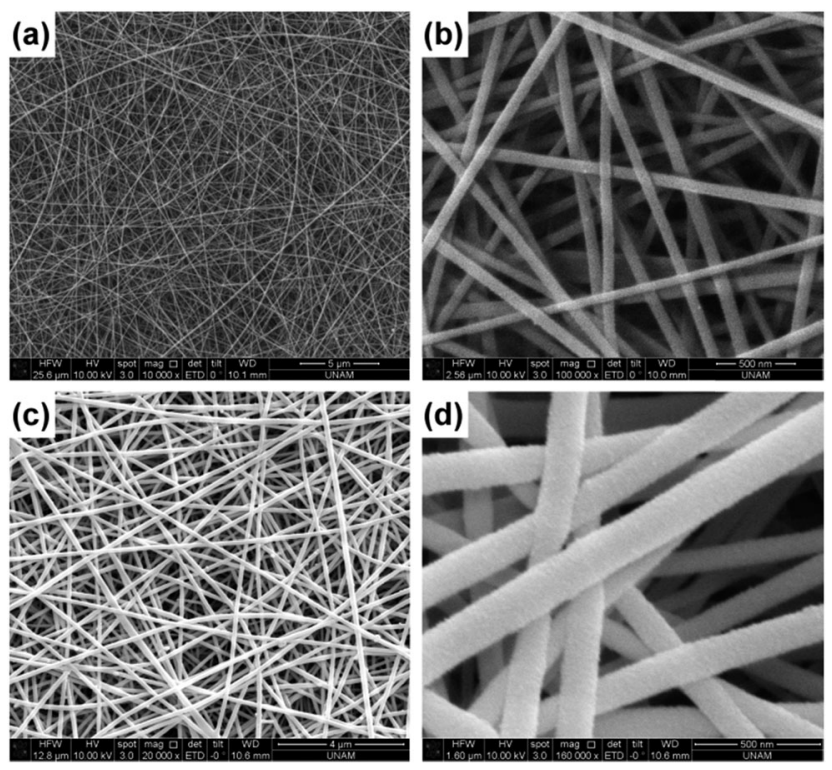

Fig. 1 Representative SEM images of (a) and (b) pristine nylon 6,6, and (c) and (d) nylon-GaN core-shell nanofibers at different magnifications.
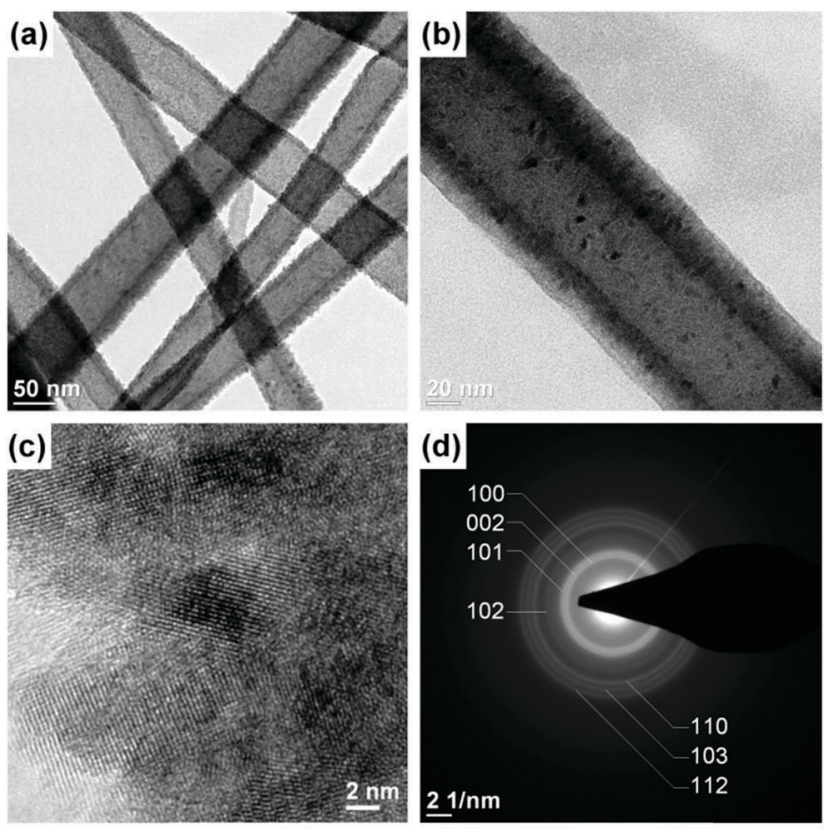

(e)

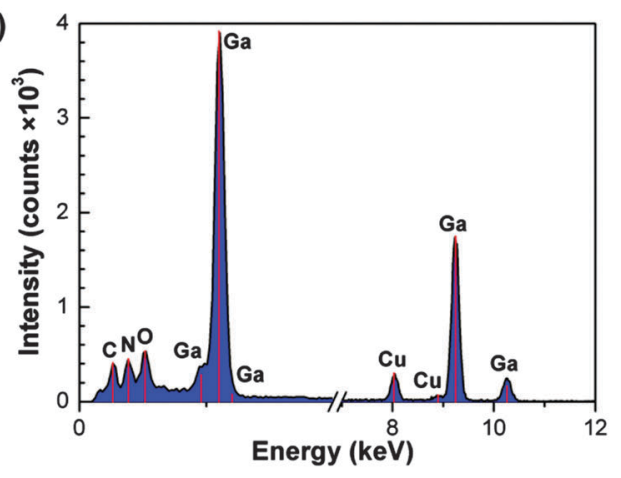

Fig. 2 Representative (a) and (b) TEM, (c) high-resolution TEM images, (d) SAED pattern, and (e) EDX spectrum of nylon-GaN core-shell nanofiber(s).

Representative TEM images of the nylon-GaN core-shell nanofiber(s) are shown in Fig. 2a and b. From Fig. 2a it is seen that a conformal GaN layer was formed on individual nanofibers with very uniform wall thicknesses along the fiber axis. In addition, the pristine nylon 6,6 nanofibers did not seem to be affected either by the process temperature or the highly reactive precursors and plasma gases. Glass-transition $\left(T_{\mathrm{g}}\right)$ and melting $\left(T_{\mathrm{m}}\right)$ temperatures of electrospun nylon 6,6 nanofibers are reported to be $85{ }^{\circ} \mathrm{C}$ and $260{ }^{\circ} \mathrm{C}$, respectively. ${ }^{57}$ Moreover, thermal degradation of the nylon 6,6 nanofibers was not observed until $400{ }^{\circ} \mathrm{C}$. ${ }^{44}$ Although the process temperature (i.e., $200{ }^{\circ} \mathrm{C}$ ) is above $T_{\mathrm{g}}$, it is lower than both $T_{\mathrm{m}}$ and the thermal decomposition temperature, which is shown to be low enough for the treatment of nanofibers without damaging their morphology. TEM investigation performed at higher magnifications revealed a relatively sharp nylon-GaN interface and did not show any contrast difference at the subsurface region of the polymeric nanofiber indicating that $\mathrm{GaMe}_{3}$ does not diffuse into the nylon 6,6 nanofibers during the process. Nevertheless we acknowledge that further supporting data such TEM and EDX analysis of fiber cross-section are needed to verify this claim. The thickness of the 
GaN layer was precisely measured from the TEM image given in Fig. 2b, and was seen to vary between $23.3 \mathrm{~nm}$ and $26.8 \mathrm{~nm}$ along the fiber axis. Besides this $\pm 14 \%$ variation in $\mathrm{GaN}$ wall thickness, TEM investigations also evidenced GaN layers that are thinner than expected on the nylon nanofibers (not shown here). A similar result is observed by us earlier in which AlN hollow nanofibers were fabricated by the deposition of an AlN layer on electrospun nylon 6,6 nanofibers via plasma-assisted ALD and subsequent calcination. ${ }^{23}$ With its inherent selflimiting growth mechanism ALD is a very unique technique that results in the non-line-of-site deposition of highly uniform and conformal thin films even on $3 \mathrm{D}$ complex nanostructures such as electrospun nanofiber mats with sub-Å thickness control. However, as in every process, the parameters must be carefully optimized to achieve the best results. The uniformity and conformality of the deposited layer can be maximized by considering the requirements of gas-solid ALD reactions occurring at the substrate surface, and accordingly adjusting precursor doses, exposure time and purging time at a given reaction temperature. The right amount of precursor must be pulsed into the reactor; for insufficient amounts the conformality would be limited by the insufficient number of reactant molecules resulting in the formation of unreacted surface sites, and for excess amounts the purging time may become impractical. The ideal purging time, which is closely related to precursor dose, exposure time and temperature, should be long enough to avoid the overlapping of different precursor molecules. On the other hand, it should be short enough to avoid desorption of precursor molecules from the substrate surface. Both of the above extreme conditions would impair the uniformity and conformality, and make accurate sub- $\AA$ thickness control impossible. Above all, the precursor molecules should be able to reach every single point on the substrate to be coated. For 3D substrates with high aspect ratios, this means that enough time should be allowed for the precursor molecules to reach the deepest corners of the substrate. ${ }^{58}$ This is usually done by exposing the substrate to precursor molecules for a certain period of time under the static vacuum conditions; i.e., the so called "exposure mode" (a trademark of Ultratech/Cambridge Nanotech Inc.). ${ }^{45}$ In the exposure mode, dynamic vacuum is switched to static vacuum just before each precursor pulse by closing the valve between the reaction chamber and the pump, allowing the substrate to be exposed to precursor molecules for a certain period of time (i.e., exposure time). This is followed by a purging period, where the chamber is switched back to dynamic vacuum for efficient evacuation/purging of excess precursor molecules and gaseous byproducts. At this point, it should also be noted that plasma-assisted ALD is known to be inferior to thermal ALD in terms of conformality due to radical recombination; therefore it does not benefit from the exposure mode as much as thermal ALD does. ${ }^{59}$ Since the GaN HCPA-ALD process has not yet been optimized for the high surface area 3D nanofiber mats, TEM investigation indicated thickness variation and/or less than expected deposition for this process. Nevertheless, the highly uniform and conformal deposition of thin GaN layers on every single electrospun nanofiber in a mat with a certain surface area and thickness can easily be envisioned by simply using the correct process parameters in light of the information given above.

The structural characterization of the deposited GaN layer was also conducted during the TEM study. Fig. 2c is a highresolution TEM image of the GaN shell of a nylon-GaN coreshell nanofiber. The image shows a polycrystalline structure with $\leq 15 \mathrm{~nm}$-sized crystals. The polycrystalline structure was also evidenced in the SAED measurements. The pattern obtained (Fig. 2d) consists of polycrystalline diffraction rings corresponding to the wurtzite (hexagonal) GaN (h-GaN) crystal structure. Measured ring diameters, theoretical values for h-GaN and the corresponding crystallographic planes are summarized in Table 1. The first ring from the center was quite thick; therefore, the inner and outer diameters of this ring were measured and found to be $6.948 \mathrm{~nm}^{-1}$ and $8.553 \mathrm{~nm}^{-1}$, corresponding to the (100) and (101) planes with calculated interplanar spacing $\left(d_{h k l}\right)$ values of $2.879 \AA$ and $2.338 \AA$, respectively. The diffraction ring corresponding to the (002) plane of h-GaN $\left(d_{h k l}=2.593 \AA\right)$ was also apparent in this relatively thick diffraction ring; however it is not distinguishable due to the merging of three individual diffraction rings. It should also be noted that when the same HCPA-ALD recipe was used on planar Si substrates, six of these seven reflections of the h-GaN phase appeared in the grazing-incidence XRD pattern. ${ }^{54}$ The presence of GaN was further confirmed by an EDX analysis performed on the TEM sample (see Fig. 2e), which indicated the presence of Ga due to the GaN shell, $\mathrm{N}$ due to the GaN shell and/or nylon core, and $\mathrm{C}$ and $\mathrm{O}$ due to the nylon core. We note that a fraction of contribution to $\mathrm{C}$ and $\mathrm{O}$ might have originated from atmospheric contamination. On the other hand oxidation of the GaN surface might also contribute to the intensity of $\mathrm{O}$ signal. The $\mathrm{Cu}$ signal in the EDX spectrum is due to the Cu TEM grid.

XRD patterns of the pristine nylon 6,6 and nylon-GaN coreshell nanofibers are given in Fig. 3. For these measurements, both nanofiber mats were peeled off from their supports (i.e., $\mathrm{Al}$ foil) and placed on a zero-background XRD sample holder. Nylon 6,6 may exist in various crystalline forms; i.e., $\alpha, \beta$, or $\gamma$-phase. ${ }^{60}$ The XRD pattern of the pristine nylon 6,6 nanofibers exhibited two distinct diffraction peaks at $\sim 20.2^{\circ}(100)$ and $\sim 22.6^{\circ}(010,110)$ and thereby confirmed the presence of an $\alpha$ phase. ${ }^{60,61}$ The $\alpha 1$ peak is related to the distance between the hydrogen-bonded chains, whereas the $\alpha 2$ peak corresponds to

Table 1 SAED results, theoretical values and corresponding crystallographic planes

\begin{tabular}{llll}
\hline $\begin{array}{llll}\text { Diameter } \\
\left(\mathrm{nm}^{-1}\right)\end{array}$ & \multicolumn{2}{l}{ Interplanar spacing, $d_{h k l}(\AA)$} & \\
\cline { 2 - 3 } & Calculated & $\begin{array}{l}\text { Theoretical } \\
\text { Corresponding } \\
\text { plane, } h k l\end{array}$ \\
\hline 6.948 & 2.879 & 2.7620 & 100 \\
8.553 & 2.338 & 2.4370 & 101 \\
10.483 & 1.9079 & 1.8910 & 102 \\
12.494 & 1.6008 & 1.5945 & 110 \\
13.591 & 1.4716 & 1.4649 & 103 \\
14.749 & 1.3560 & 1.3582 & 112
\end{tabular}

${ }^{a}$ Hexagonal GaN, ICDD reference code: 00-025-1133. 


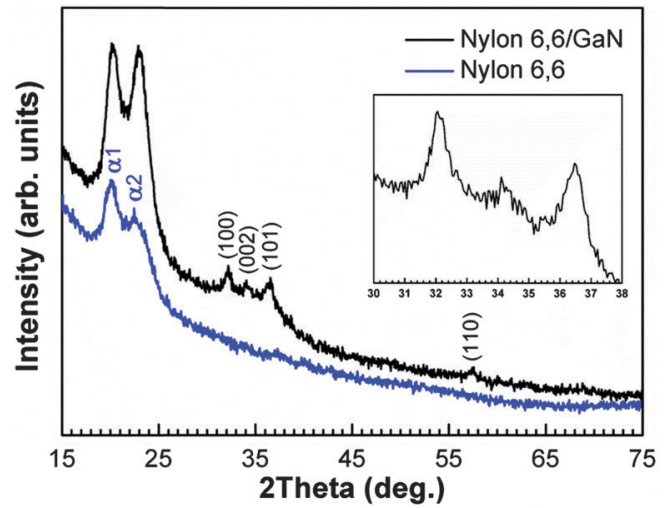

Fig. 3 XRD patterns of freestanding pristine nylon 6,6 and nylon-GaN core-shell nanofibers. The inset shows the XRD pattern of freestanding nylon-GaN core-shell nanofiber mat recorded with an exaggerated counting time (i.e., $2000 \mathrm{~s}$ ) within the $2 \theta$ range of $30-38^{\circ}$.

the separation of hydrogen-bonded sheets. ${ }^{60}$ The absence of the reflections of the $\beta$ phase at $2 \theta$ values of $\sim 12^{\circ}$ and $\sim 19^{\circ}$ or the $\gamma 1$ peak $\left(2 \theta=\sim 13^{\circ}\right)$ and $\gamma 2$ peak $\left(2 \theta=\sim 22^{\circ}\right)^{60}$ indicates that the nylon 6,6 nanofibers in the electrospun mat have a pure triclinic $\alpha$ phase comprising hydrogen-bonded sheets. ${ }^{62}$ The peaks corresponding to the $\alpha$ phase of nylon 6,6 were also apparent in the XRD pattern of nylon-GaN core-shell nanofiber mat. However, in addition, we also observed peaks corresponding to the h-GaN phase. The reflections (100), (002), (101), and (110) of the h-GaN phase appeared at $\sim 2 \theta$ values of $32.2^{\circ}, 34.1^{\circ}, 36.6^{\circ}$, and $57.5^{\circ}$, respectively. These results are in very good agreement with the SAED results given in Fig. $2 \mathrm{~d}$ and Table 1.

Chemical compositions and bonding states of the pristine nylon 6,6 and nylon-GaN core-shell nanofibers were studied using XPS. XPS survey scans of pristine nylon 6,6 and nylonGaN core-shell nanofibers are given in Fig. 4a. The survey spectrum of the pristine nylon 6,6 nanofibers indicated the presence of $\mathrm{N}, \mathrm{C}$ and $\mathrm{O}$ elements as anticipated. The elemental composition of the sample was determined by the quantification of this spectrum as 11.52 at\% N, 76.92 at\% $\mathrm{C}$ and 11.56 at\% $\mathrm{O}$, which is quite close to the theoretical values of 12.5 at\% N, 75 at\% C and 12.5 at\% O. ${ }^{63}$ For the nylon-GaN coreshell nanofibers; on the other hand, 20.95 at $\% \mathrm{Ga}, 28.20$ at $\% \mathrm{~N}$, 38.22 at\% $\mathrm{C}$, and 12.64 at\% $\mathrm{O}$ were detected. It should be noted that for the GaN thin film deposited on a Si substrate at the same temperature using identical HCPA-ALD parameters, the XPS survey scan detected 7.92 at\% $\mathrm{C}$ on the film surface. As has already been discussed in a previous study, ${ }^{23}$ a relatively large $\mathrm{X}$-ray beam interacts $(\sim 400 \mu \mathrm{m}$ spot size $)$ with a large number of core-shell nanofibers during the analysis, which might have discontinuities or cracks on the shell layer due to the method of sample preparation. Therefore, although XPS is a surface analysis technique that collects data from the top $\sim 5$ to $10 \mathrm{~nm}$ depending on the material, it should not be surprising in an XPS analysis to observe signal(s) from the underlying core. Therefore, the $\mathrm{C}$, $\mathrm{N}$ and $\mathrm{O}$ amounts reported here should be considered as collective of the nylon core and GaN shell, with a smaller contribution from (a)

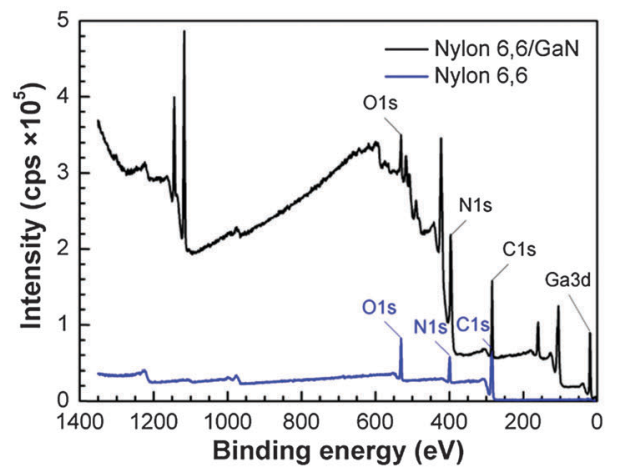

(b)

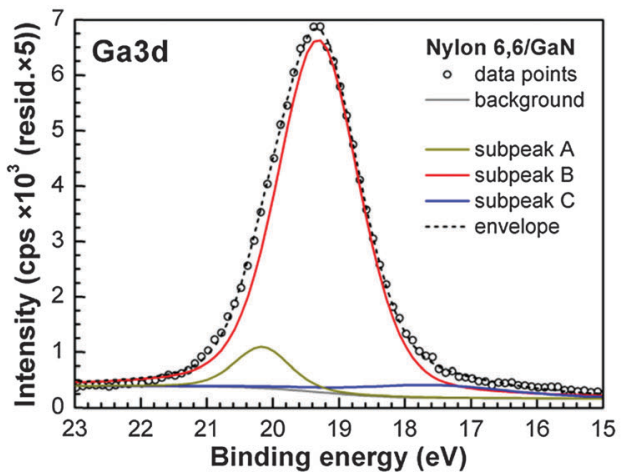

(c)

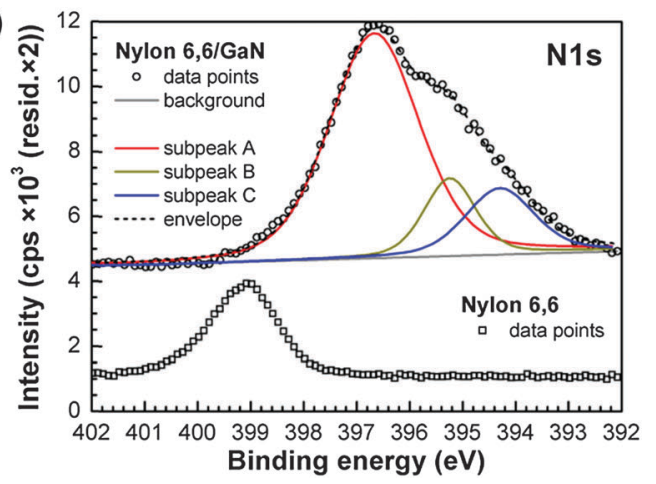

Fig. 4 (a) XPS wide energy survey scans of pristine nylon 6,6 and nylon-GaN core-shell nanofibers. (b) Ga3d high-resolution XPS scan of nylon-GaN core-shell nanofibers, and (c) N1s high-resolution XPS scans of pristine nylon 6,6 and nylon-GaN core-shell nanofibers.

the former. Fig. 4b is the Ga3d high-resolution XPS scan of nylonGaN core-shell nanofibers, which was fitted similarly to its thin film counterpart ${ }^{54}$ using three subpeaks located at $20.16 \mathrm{eV}$ (subpeak A), $19.31 \mathrm{eV}$ (subpeak B) and $17.63 \mathrm{eV}$ (subpeak C). Subpeaks A and B were assigned to the $\mathrm{Ga}-\mathrm{O}^{64,65}$ and $\mathrm{Ga}-\mathrm{N}^{64-66}$ bonds, respectively, whereas subpeak $\mathrm{C}$ was found to be related to the contribution from the N2s core level. ${ }^{65,67}$ N1s highresolution XPS scans of pristine nylon 6,6 and nylon-GaN core-shell nanofibers are shown in Fig. 4c. The high-resolution XPS spectrum of pristine nylon 6,6 nanofibers exhibited a peak at $\sim 399 \mathrm{eV}$, which is assigned to the NCO, amide bond. ${ }^{63}$ This peak is absent in the high-resolution XPS spectrum of nylon-GaN coreshell nanofibers, which was fitted by three subpeaks located at $396.67 \mathrm{eV}$ (subpeak A), $395.24 \mathrm{eV}$ (subpeak B) and $394.30 \mathrm{eV}$ (subpeak C). Subpeak A corresponds to the N-Ga bond, ${ }^{68}$ whereas subpeaks B and C were identified as the Auger Ga peaks. ${ }^{69}$ 


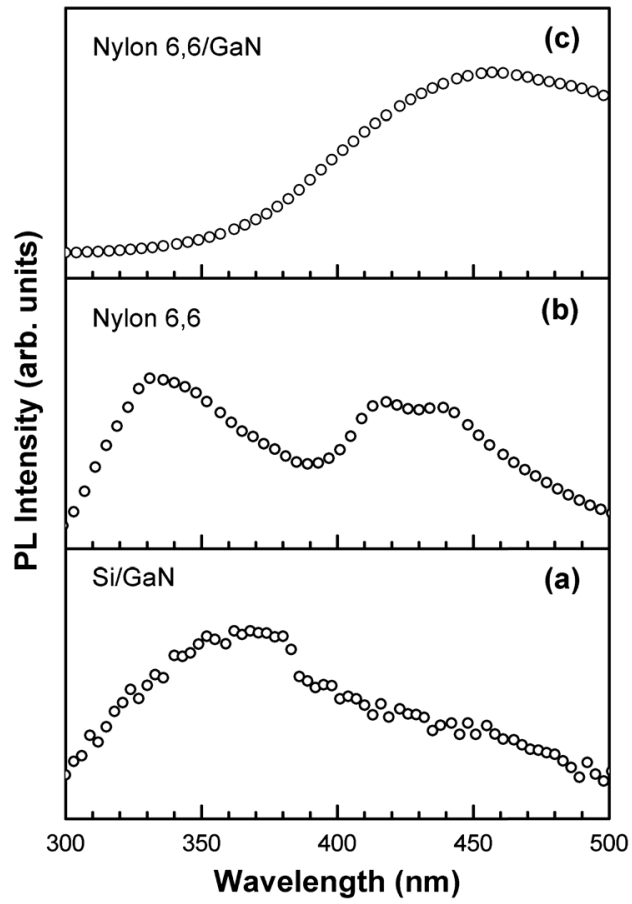

Fig. 5 PL emission spectra of (a) 20 nm-thick GaN thin film deposited on $\mathrm{Si}$, (b) pristine nylon 6,6 nanofibers, and (c) nylon-GaN core-shell nanofibers.

Note that the high-resolution N1s scan of the GaN film deposited on a Si substrate via HCPA-ALD at the same temperature was also fitted using three subpeaks having locations similar to those reported here for nylon-GaN core-shell nanofibers. ${ }^{54}$

The characteristic PL emission spectra of $\sim 20 \mathrm{~nm}$-thick GaN thin film deposited on Si, pristine nylon 6,6 nanofibers and nylon-GaN core-shell nanofibers are given in Fig. 5. The GaN spectrum (Fig. 5a) exhibited a broad spectral feature centered at $368 \mathrm{~nm}$, which results from the main band gap emission in the GaN thin film. The less steep slope in the 400-450 $\mathrm{nm}$ spectral region, on the other hand, might be designated to bulk and surface related impurities and/or defect structures. As seen in Fig. 5b, two emission peaks were observed at $336 \mathrm{~nm}$ and between 418 and $440 \mathrm{~nm}$ for pristine nylon 6,6 nanofibers. The relative PL intensity of the pristine nylon 6,6 nanofibers was significantly higher than that detected for the GaN thin film sample. Although the observed emission at low wavelengths was not strong for the nylon-GaN core-shell nanofibers (Fig. 5c), the PL intensity detected at $450 \mathrm{~nm}$ was significantly higher than those recorded from pristine nylon 6,6 nanofibers and the GaN thin film.

The representative photograph of the fabricated nylon-GaN core-shell nanofiber mat is given in Fig. 6 . The fabricated mat could be easily peeled off from its support (i.e., Al foil); moreover, it could be easily handled and folded due to its flexible profile in the freestanding state. The mechanical properties of pristine nylon 6,6 and nylon-GaN core-shell nanofiber mats were investigated by dynamic mechanical analysis (DMA). Tensile test results are summarized in Table S1 (ESI $\dagger$ ). The nylon-GaN core-shell nanofiber mat exhibited significantly poor tensile

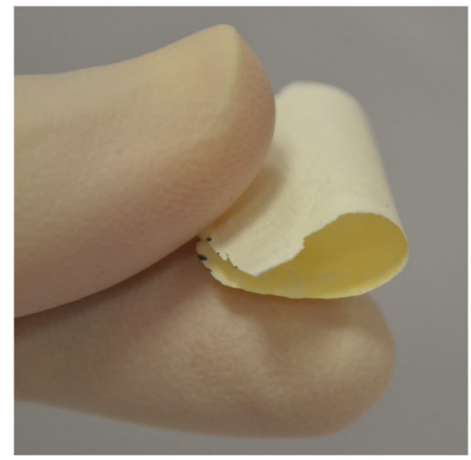

Fig. 6 The representative photograph of the freestanding nylon-GaN core-shell nanofiber mat. The fabricated mat can easily be handled and folded owing to the flexible organic cores.

properties as compared to those of the pristine nylon 6,6 nanofiber mat. However, the hybrid nanofibrous structure responded to the applied stress with proportional strain (see Fig. S1(a), ESI $\dagger$ ), indicating an elastic behavior. The storage moduli of nanofiber mats are given in Fig. S1(b) (ESI $\dagger$ ) as a function of temperature. The storage modulus values of both samples decreased within the temperature range of $75-200{ }^{\circ} \mathrm{C}$ due to the segmental motion of polymer chains. The storage modulus of pristine nylon 6,6 nanofiber mat was observed to be higher than that of the hybrid nanofiber mat, indicating deteriorated mechanical properties for nylon-GaN core-shell nanofibers. The difference between the mechanical behaviors of two samples is possibly because of the inorganic nature of the GaN shell part, which led to reduction at the elastic feature of pristine nylon nanofibers; in addition, a slight degradation of the polymeric core is also quite possible since the nylon 6,6 core was exposed to $200{ }^{\circ} \mathrm{C}$ for an extended period of time $(\sim 17 \mathrm{~h})$ in the ALD chamber. Nevertheless, DMA results show that these polymer-GaN hybrid nanofibers fabricated using the combination of electrospinning and HCPA-ALD processes exhibit decent mechanical integrity for practical applications. In addition, the inherent mechanical properties of pristine nylon 6,6 nanofiber mat could be maintained for the fabricated hybrid nanostructures by simply lowering the HCPA-ALD temperature of the GaN shell layer.

\section{Conclusions}

Polymer (nylon 6,6)-GaN core-shell nanofibers were fabricated using the combination of electrospinning and HCPA-ALD processes. Morphological investigation carried out using SEM revealed bead-free nylon 6,6 nanofibers with an average fiber diameter of $\sim 70 \mathrm{~nm}$. Subsequently deposited GaN layer perfectly replicated the fiber morphology of the polymeric 3D substrate, forming nylon-GaN core-shell nanofibers with an average fiber diameter of $\sim 123 \mathrm{~nm}$. TEM studies showed slightly non-uniform or less than expected thicknesses for the GaN layers on nylon 6,6 nanofibers, indicating the need for the optimization of HCPA-ALD process parameters such as precursor doses, 
exposure time and purging time for these high specific surface area 3D substrates with a very high aspect ratio. The presence of GaN on nylon 6,6 nanofibers was evidenced by elemental analyses carried out using EDX and XPS. High-resolution Ga3d and N1s XPS spectra revealed Ga-N and N-Ga bonding states with peaks located at $19.31 \mathrm{eV}$ and $396.67 \mathrm{eV}$, respectively. The structure of the GaN shell layer was examined using high-resolution TEM, SAED and XRD, all of which indicated a polycrystalline layer with wurtzite crystal structure. Nylon-GaN core-shell nanofiber mats were easily handled in their freestanding state owing to their flexible cores and showed adequate mechanical integrity as determined by DMA. Moreover, the flexible core-shell GaN nanostructures were fabricated at a processing temperature (i.e., $200{ }^{\circ} \mathrm{C}$ ) much lower than that needed for the preparation of GaN nanofibers using conventional techniques. These organic-inorganic semiconducting nanofibers, therefore, have the potential to substitute brittle ceramic GaN nanofibers in various electronic and optoelectronic devices such as gas sensors and UV photodetectors.

\section{Acknowledgements}

S. Vempati thanks The Scientific and Technological Research Council of Turkey (TUBITAK) (TUBITAK-BIDEB 2221, Fellowships for Visiting Scientists and Scientists on Sabbatical) for fellowship. E. Goldenberg gratefully acknowledges the financial support from TUBITAK (TUBITAK-BIDEB 2232, Project \#113C020). N. Biyikli thanks EU FP7-Marie Curie-IRG for funding NEMSmart (PIRG05-GA-2009-249196). T. Uyar thanks EU FP7-Marie CurieIRG (NANOWEB, PIRG06-GA-2009-256428) and The Turkish Academy of Sciences-Outstanding Young Scientists Award Program (TUBA-GEBIP) for partial funding. M. Guler from UNAM is acknowledged for TEM imaging.

\section{Notes and references}

1 S. C. Jain, M. Willander, J. Narayan and R. Van Overstraeten, J. Appl. Phys., 2000, 87, 965-1006.

2 S. Barth, F. Hernandez-Ramirez, J. D. Holmes and A. Romano-Rodriguez, Prog. Mater. Sci., 2010, 55, 563-627.

3 C.-C. Chen, C.-C. Yeh, C.-H. Chen, M.-Y. Yu, H.-L. Liu, J.-J. Wu, K.-H. Chen, L.-C. Chen, J.-Y. Peng and Y.-F. Chen, J. Am. Chem. Soc., 2001, 123, 2791-2798.

4 Z. Zhong, F. Qian, D. Wang and C. M. Lieber, Nano Lett., 2003, 3, 343-346.

5 T. Kuykendall, P. J. Pauzauskie, Y. Zhang, J. Goldberger, D. Sirbuly, J. Denlinger and P. Yang, Nat. Mater., 2004, 3, 524-528.

6 C.-C. Chen and C.-C. Yeh, Adv. Mater., 2000, 12, 738-741.

7 F. Qian, Y. Li, S. Gradečak, D. Wang, C. J. Barrelet and C. M. Lieber, Nano Lett., 2004, 4, 1975-1979.

8 B. Xu, D. Yang, F. Wang, J. Liang, S. Ma and X. Liu, Appl. Phys. Lett., 2006, 89, 074106.

9 X. Duan and C. M. Lieber, J. Am. Chem. Soc., 2000, 122, 188-189.
10 Y. Huang, X. Duan, Y. Cui and C. M. Lieber, Nano Lett., 2002, 2, 101-104.

11 G. S. Cheng, L. D. Zhang, Y. Zhu, G. T. Fei, L. Li, C. M. Mo and Y. Q. Mao, Appl. Phys. Lett., 1999, 75, 2455-2457.

12 J. Goldberger, R. He, Y. Zhang, S. Lee, H. Yan, H.-J. Choi and P. Yang, Nature, 2003, 422, 599-602.

13 C. Youtsey, L. T. Romano and I. Adesida, Appl. Phys. Lett., 1998, 73, 797-799.

14 K. J. Lee, J. Lee, H. Hwang, Z. J. Reitmeier, R. F. Davis, J. A. Rogers and R. G. Nuzzo, Small, 2005, 1, 1164-1168.

15 A. Meléndez, K. Morales, I. Ramos, E. Campo and J. J. SantiagoAvilés, IEEE Conf. Nanotechnol., 9th, 2009, 5394610, 269-272.

16 A. Meléndez, K. Morales, I. Ramos, E. Campo and J. J. Santiago-Avilés, Proc. SPIE-Int. Soc. Opt. Eng., 2009, 7402, 740210.

17 J. L. Robles-García, A. Meléndez, D. Yates, J. J. Santiago-Avilés, I. Ramos and E. M. Campo, Proc. SPIE-Int. Soc. Opt. Eng., 2011, 8036, 80360F.

18 E. M. Campo, J. Poplawsky, A. Meléndez, J. L. Robles-García, I. Ramos, D. Yates, J. E. Fischer and J. J. Santiago-Avilés, RSC Adv., 2014, 4, 2634-2639.

19 E. M. Campo, A. Meléndez, K. Morales, J. Poplawsky, J. J. Santiago-Avilés and I. Ramos, Proc. SPIE-Int. Soc. Opt. Eng., 2010, 7729, 77290T.

$20 \mathrm{H}$. Wu, Y. Sun, D. Lin, R. Zhang, C. Zhang and W. Pan, Adv. Mater., 2009, 21, 227-231.

21 X. Luo, X. Zheng, D. Wang, Y. Zhang, H. Cheng, X. Wang, H. Zhuang and Y. Lou, Sens. Actuators, B, 2014, 202, 1010-1018.

22 Q. Peng, X.-Y. Sun, J. C. Spagnola, G. K. Hyde, R. J. Spontak and G. N. Parsons, Nano Lett., 2007, 7, 719-722.

23 C. Ozgit-Akgun, F. Kayaci, I. Donmez, T. Uyar and N. Biyikli, J. Am. Ceram. Soc., 2013, 96, 916-922.

24 A. Haider, C. Ozgit-Akgun, F. Kayaci, A. K. Okyay, T. Uyar and N. Biyikli, APL Mater., 2014, 2, 096109.

25 I. Donmez, F. Kayaci, C. Ozgit-Akgun, T. Uyar and N. Biyikli, J. Alloys Compd., 2013, 559, 146-151.

26 B.-S. Lee, W.-S. Kim, D.-H. Kim, H.-C. Kim, S.-H. Hong and W.-R. Yu, Smart Mater. Struct., 2011, 20, 105019.

27 W.-S. Kim, B.-S. Lee, D.-H. Kim, H.-C. Kim, W.-R. Yu and S.-H. Hong, Nanotechnology, 2010, 21, 245605.

28 G. M. Kim, S.-M. Lee, G. H. Michler, H. Roggendorf, U. Gösele and M. Knez, Chem. Mater., 2008, 20, 3085-3091.

29 S.-W. Choi, J. Y. Park, C. Lee, J. G. Lee and S. S. Kim, J. Am. Ceram. Soc., 2011, 94, 1974-1977.

30 A. Katoch, J.-H. Kim and S. S. Kim, ACS Appl. Mater. Interfaces, 2014, 6, 21494-21499.

31 J. Y. Park, S.-W. Choi and S. S. Kim, Nanotechnology, 2010, 21, 475601.

32 S. Cho, D.-H. Kim, B.-S. Lee, J. Jung, W.-R. Yu, S.-H. Hong and S. Lee, Sens. Actuators, B, 2012, 162, 300-306.

33 A. Katoch, S.-W. Choi and S. S. Kim, Nanotechnology, 2014, 25, 455504.

34 G.-M. Kim, S.-M. Lee, M. Knez and P. Simon, Thin Solid Films, 2014, 562, 291-298.

35 A. Katoch, S.-W. Choi, G.-J. Sun, H. W. Kim and S. S. Kim, Nanotechnology, 2014, 25, 175501. 
36 E. Santala, M. Kemell, M. Leskelä and M. Ritala, Nanotechnology, 2009, 20, 035602.

37 A. A. Chaaya, M. Bechelany, S. Balme and P. Miele, J. Mater. Chem. A, 2014, 2, 20650-20658.

38 S.-W. Choi, J. Y. Park and S. S. Kim, Nanotechnology, 2009, 20, 465603.

39 J. Y. Park, S.-W. Choi, J.-W. Lee, C. Lee and S. S. Kim, J. Am. Ceram. Soc., 2009, 92, 2551-2554.

40 F. Kayaci, S. Vempati, C. Ozgit-Akgun, I. Donmez, N. Biyikli and T. Uyar, Nanoscale, 2014, 6, 5735-5745.

41 I. M. Szilágyi, E. Santala, M. Heikkilä, V. Pore, M. Kemell, T. Nikitin, G. Teucher, T. Firkala, L. Khriachtchev, M. Räsänen, M. Ritala and M. Leskelä, Chem. Vap. Deposition, 2013, 19, 149-155.

42 Q. Du, J. Wu and H. Yang, ACS Catal., 2014, 4, 144-151.

43 Q. Peng, X.-Y. Sun, J. C. Spagnola, C. Saquing, S. A. Khan, R. J. Spontak and G. N. Parsons, ACS Nano, 2009, 3, 546-554.

44 F. Kayaci, C. Ozgit-Akgun, I. Donmez, N. Biyikli and T. Uyar, ACS Appl. Mater. Interfaces, 2012, 4, 6185-6194.

45 F. Kayaci, C. Ozgit-Akgun, N. Biyikli and T. Uyar, RSC Adv., 2013, 3, 6817-6820.

46 F. Kayaci, S. Vempati, C. Ozgit-Akgun, N. Biyikli and T. Uyar, Appl. Catal., B, 2014, 156-157, 173-183.

47 F. Kayaci, S. Vempati, I. Donmez, N. Biyikli and T. Uyar, Nanoscale, 2014, 6, 10224-10234.

48 M. Asif Khan, R. A. Skogman, J. M. Van Hove, D. T. Olson and J. N. Kuznia, Appl. Phys. Lett., 1992, 60, 1366-1368.

49 N. H. Karam, T. Parodos, P. Colter, D. McNulty, W. Rowland, J. Schetzina, N. El-Masry and S. M. Bedair, Appl. Phys. Lett., 1995, 67, 94-96.

50 Y. Kumagai, M. Mayumi, A. Koukitu and H. Seki, Appl. Surf. Sci., 2000, 159-160, 427-431.

51 O. H. Kim, D. Kim and T. Anderson, J. Vac. Sci. Technol., A, 2009, 27, 923-928.

52 C. Ozgit, I. Donmez, M. Alevli and N. Biyikli, J. Vac. Sci. Technol., A, 2012, 30, 01A124.
53 C. Ozgit-Akgun, I. Donmez and N. Biyikli, ECS Trans., 2013, 58, 289-297.

54 C. Ozgit-Akgun, E. Goldenberg, A. K. Okyay and N. Biyikli, J. Mater. Chem. C, 2014, 2, 2123-2136.

55 S. Bolat, C. Ozgit-Akgun, B. Tekcan, N. Biyikli and A. K. Okyay, Appl. Phys. Lett., 2014, 104, 243505.

56 B. Tekcan, C. Ozgit-Akgun, S. Bolat, N. Biyikli and A. K. Okyay, Opt. Eng., 2014, 53, 107106.

57 A. Baji, Y.-W. Mai, S.-C. Wong, M. Abtahi and X. Du, Compos. Sci. Technol., 2010, 70, 1401-1409.

58 R. G. Gordon, D. Hausmann, E. Kim and J. Shepard, Chem. Vap. Deposition, 2003, 9, 73-78.

59 J. Musschoot, J. Dendooven, D. Deduytsche, J. Haemers, G. Buyle and C. Detavernier, Surf. Coat. Technol., 2012, 206, 4511-4517.

60 J. Li, Y. Zuo, X. Cheng, W. Yang, H. Wang and Y. Li, J. Mater. Sci.: Mater. Med., 2009, 20, 1031-1038.

61 C. P. Leo, A. Linggawati, A. W. Mohammad and Z. Ghazali, J. Appl. Polym. Sci., 2011, 122, 3339-3350.

62 Q. Zhang, Z.-Z. Yu, M. Yang, J. Ma and Y.-W. Mai, J. Polym. Sci., Part B: Polym. Phys., 2003, 41, 2861-2869.

63 M. C. Burrell and J. J. Chera, Surf. Sci. Spectra, 1999, 6, 13-17. 64 S. D. Wolter, B. P. Luther, D. L. Waltemyer, C. Önneby, S. E. Mohney and R. J. Molnar, Appl. Phys. Lett., 1997, 70, 2156-2158.

65 V. Matolín, S. Fabík, J. Glosík, L. Bideux, Y. Ould-Metidji and B. Gruzza, Vacuum, 2004, 76, 471-476.

66 P. Kumar, M. Kumar, G. B. R. Mehta and S. M. Shivaprasad, Appl. Surf. Sci., 2009, 256, 517-520.

67 W. R. L. Lambrecht, B. Segall, S. Strite, G. Martin, A. Agarwal, H. Morkoç and A. Rockett, Phys. Rev. B: Condens. Matter Mater. Phys., 1994, 50, 14155-14160.

68 Z. Majlinger, a. Bozanic, M. Petravic, K.-J. Kim, B. Kim and Y.-W. Yang, Vacuum, 2009, 84, 41-44.

69 G. Moldovan, I. Harrison, M. Roe and P. D. Brown, Inst. Phys. Conf. Ser., 2004, 179, 115-118. 